\title{
Detection of avian reoviruses in wild birds in Poland
}

\author{
Natalia Styś-Fijoł, Wojciech Kozdruń, Hanna Czekaj \\ Department of Poultry Diseases, \\ National Veterinary Research Institute, 24-100 Pulawy, Poland \\ natalia.stys@ piwet.pulawy.pl
}

Received: April 10, 2017

Accepted: August 17, 2017

\begin{abstract}
Introduction: The purpose of this study was to determine the occurrence of avian reovirus (ARV) infections in wild birds in Poland and attempt to propagate the selected ARV strains in chicken embryo kidney (CEK) cells or chicken SPF embryos. Material and Methods: The study included 192 wild birds representing 32 species, collected between 2014 and 2016. A part of the S4 segment encoding the $\sigma \mathrm{NS}$ protein of avian reoviruses (ARVs) isolated from different species of wild birds from that period was amplified. Results: The presence of ARV was demonstrated in 58 (30.2\%) wild birds belonging to nine orders. The isolated strains were propagated in chicken embryos by yolk sac inoculation, and CPE was induced in the infected CEK monolayer. Agar gel precipitation showed that two ARV isolates from rock pigeon and mute swan shared a common groupspecific antigen with chicken reovirus S1133. Specific products of predicted size were found in two ARV isolates from the chicken embryo passage and 13 ARVs isolated from CEK cells. Conclusion: The study indicates the high prevalence of ARV among wild birds in Poland and its possible transmission to farmed birds.
\end{abstract}

Keywords: wild birds, avian reovirus, Poland.

\section{Introduction}

In many parts of the world avian orthoreovirus $(\mathrm{ARV})$ can be a cause of viral arthritis/tenosynovitis in chickens and turkeys $(13,21)$. However, the virus has also been isolated from birds showing several other disease conditions such as runting-stunting syndrome, hepatitis, myocarditis, and enteric and respiratory diseases in commercial poultry flocks $(1,22)$.

ARV infections have been increasingly diagnosed in wild avian species (4). Several reports have described ARV as a cause of serious diseases and mortality in free-living corvid species. Lawson et al. (10) presented a case of ARV infection in a wild magpie (Pica pica) from England. Recently, a novel orthoreovirus strains have been isolated from partridge (Perdix perdix) and brown-eared bulbul (Hypsipetes amaurotis) $(9,18)$. In many cases, association of ARV infection with disease/condition in wild birds has not been established, because no experimental studies have been performed. Little is known about the epizootiology of reoviruses in wild bird populations, but asymptomatic carriers have been implicated as potential sources of infection in poultry. Transmission to other birds inhabiting contaminated environment is possible because infected birds excrete significant amounts of the virus in their droppings (6).

ARVs belong to the genus Orthoreovirus in the Reoviridae family (15). They are characterised by medium-sized $(70-80 \mathrm{~nm})$ icosahedral virion and the double-stranded RNA genome consisting of 10-12 segments (20). The segmented genome encodes eight structural proteins $(\lambda \mathrm{A}, \lambda \mathrm{B}, \lambda \mathrm{C}, \mu \mathrm{A}, \mu \mathrm{B}, \sigma \mathrm{A}, \sigma \mathrm{B}, \sigma \mathrm{C})$ and four non-structural proteins ( $\mu \mathrm{NS}, \mathrm{P} 10, \mathrm{P} 17$, and $\sigma \mathrm{NS})$ (14). The ssRNA-binding nonstructural protein $\sigma \mathrm{NS}$ is encoded by ARV S4 genome segment. This protein is present in large ribonucleoprotein complexes in the cytoplasm of infected cells and likely plays a key role in RNA packaging and virus replication (2). The site of primary ARV replication is the epithelium of the small intestine and bursa of Fabricius, after which the virus spreads within $24-48 \mathrm{~h}$ to other tissues and organs. The infection is pantropic (19).

The objective of this study was to investigate the occurrence of ARV infections in wild birds in Poland and propagate selected ARV strains in chicken embryo 
kidney (CEK) cells or chicken SPF embryos. In Poland, studies on the occurrence of ARV in wild bird population have not been conducted so far due to the low availability of research material. This is the first report describing the detection and isolation of $\mathrm{ARV}$ in free-living birds in Poland.

\section{Material and Methods}

Birds and samples. A total of 192 dead wild birds obtained from ornithological stations and wild birds rehabilitation centres were used in the investigations between 2014 and 2016. The predominant groups among the tested birds were the Passeriformes order represented by 72 birds of different species and Ciconiiformes represented by 61 white storks (Ciconia ciconia). The remaining birds represented other orders and species (Table 1). During necropsy, sections of the heart, lungs, liver, spleen, gizzard, intestines, and kidneys were collected for molecular biology examinations and virus isolation. The sections were homogenised as $10 \%(\mathrm{w} / \mathrm{v})$ suspensions in sterile phosphate-buffered saline (PBS) and then centrifuged at $6,000 \times \mathrm{g}$ for $10 \mathrm{~min}$. The obtained supernatant was stored at $-20^{\circ} \mathrm{C}$ for further investigations.

RNA extraction and RT-PCR. Total cellular RNA was extracted from the homogenates of internal organs, embryonic fluids, and membranes collected from infected chicken SPF embryos and cell culture supernatant using the RNAsy Mini Kit (Qiagen, Germany) according to manufacturer's protocol. The extracted RNA was used for the amplification reaction of a fragment of non-structural sigma NS gene of ARV using previously published primers (23). Amplification was performed in a T-Gradient Biometra Thermocycler (Biometra, Germany) using a One Step RT-PCR kit. The reaction was conducted in a $25 \mu \mathrm{L}$ reaction mixture containing $2 \mu \mathrm{L}$ of template RNA, $10 \mu \mathrm{L}$ of RNase-free water, $4 \mu \mathrm{L}$ of $5 \mathrm{x}$ RT-PCR buffer, $1 \mu \mathrm{L}$ of dNTP mix (10 mM each dNTP), $1 \mu \mathrm{L}$ of enzyme mix, $5 \mu \mathrm{L}$ of $5 \times$ Q-solution, and $1 \mu \mathrm{L}$ of each of the two primers. RT-PCR conditions were as follows: reverse transcription step at $50^{\circ} \mathrm{C}$ for $30 \mathrm{~min}$, initial denaturation at $94^{\circ} \mathrm{C}$ for $15 \mathrm{~min}$, then 40 cycles at $95^{\circ} \mathrm{C}$ for $1 \mathrm{~min}, 60^{\circ} \mathrm{C}$ for $1 \mathrm{~min}, 72^{\circ} \mathrm{C}$ for $1 \mathrm{~min}$, and single cycle at $72^{\circ} \mathrm{C}$ for $10 \mathrm{~min}$. RNA extracted from CEK cell culture inoculated with the $\mathrm{S} 1133$ strain was used as positive control, whereas non-inoculated CEK cell cultures served as negative control.

PCR product analysis. The ARV S4 segment amplified by RT-PCR was separated in $2 \%$ agarose gels in GelRed under $120 \mathrm{~V}$ for $40 \mathrm{~min}$. The size of the amplicons was compared with the MassRuler DNA Ladder Mix (Thermo Scientific, USA). The results were visualised using transilluminator UV (GenoSmart, VWR, Germany), then photographed and analysed. The results were considered as positive when the RT-PCR product in RNA samples extracted from internal organs had a predicted size of $522 \mathrm{bp}$.

Virus isolation in chicken SPF embryos. The supernatants of internal organs homogenates were diluted and filtered through $0.45 \mu \mathrm{m}$ syringe filters. The filtered suspension was injected into yolk sack of 5-6-day-old specific pathogen free (SPF) chicken embryos ( $0.2 \mathrm{~mL} / \mathrm{embryo})$. The embryos were candled daily for seven days. The amino-allantoic fluids, membranes, livers, and spleens of infected embryos were collected for further study.

Agar gel immunodiffusion test. Serological identification of ARV was performed by agar gel immunodiffusion test (AGID). The antiserum specific for S1133 reference chicken reovirus strain (Charles River Laboratories, USA) was used to detect reovirus antigen in hepatic homogenates, embryonic fluids, and membranes of infected embryos. Immunodiffusion test was performed to identify reoviruses in a layer of $1.5 \%$ agar gel supplemented with $8 \% \mathrm{NaCl}$. The slides were incubated for $24-48 \mathrm{~h}$ in a humidity chamber at room temperature.

Cell cultures. The cultures of chicken embryo kidney (CEK) cells were prepared from 18-19-day-old SPF chicken embryos (Lohman, Germany), according to the standard procedure. The growth medium was Eagle's minimum essential medium (MEM) supplemented with $10 \%$ foetal bovine serum and $1 \%$ addition of antibiotics (Antibiotic-Antimycotic, SigmaAldrich, USA). MEM with the antibiotics was used as the maintenance medium. CEK monolayer was inoculated with homogenates of internal organs centrifuged, diluted $10^{-1}$, and filtered through the Millipore $0.45 \mu \mathrm{m}$ filter. The infected cultures were incubated at $37.5^{\circ} \mathrm{C}$ in $5 \% \mathrm{CO}_{2}$ and were observed daily under a microscope to determine a cytopathic effect (CPE). Three passages of the virus were conducted in cell cultures, and then the cells and supernatants were used for further analyses.

\section{Results}

All collected birds were necropsied. According to the information obtained from ornithologists, the birds died due to various causes and frequently had different fractures and other injures. Post-mortem examination often revealed swollen liver and spleen with the presence of liver necrosis. The lesions were characteristic of ARV infection. In some birds, gouty kidneys and enteritis were found.

In the study, $\sigma \mathrm{NS}$-encoding gene was targeted for diagnostic analysis because it shows less divergence within S class genome of ARV (11). The molecular examination revealed the presence of ARV genetic material in internal organs collected from 58 (30.2\%) out of 192 examined wild birds representing different species (Table 1). The presence of ARVs was found in 
$88(15.4 \%)$ samples of different internal organs. Samples of the lungs $(23.6 \%)$, spleen $(20.6 \%)$, and heart $(20.4 \%)$ gave the highest number of positive results for ARV NS gene (Table 2).

Two homogenates of internal organs from birds with positive result in RT-PCR were used for the infection of chicken SPF embryos. Three days after yolk sack inoculation with kidney homogenate from rock pigeon, one of the five embryos died. The chicken embryos infected with intestine homogenate from white stork survived until the end of the experiment. All embryos exhibited subcutaneous haemorrhages in the muscles and olive green pigmentation of the liver parenchyma.

Table 1. Overview of the samples studied and RT-PCR results

\begin{tabular}{|c|c|c|c|c|c|}
\hline Order & Species - Latin name & Species - English name & $\begin{array}{l}\text { Number of birds } \\
\text { tested }\end{array}$ & $\begin{array}{l}\text { Number of } \\
\text { positive birds }\end{array}$ & $\begin{array}{l}\text { Percentage of } \\
\text { positive birds* }\end{array}$ \\
\hline Ciconiiformes & Ciconia ciconia & white stork & 61 & 32 & 52.4 \\
\hline Pelecaniformes & Ardea cinerea & grey heron & 1 & 1 & - \\
\hline Columbiformes & Columba liva & rock pigeon & 13 & 2 & 15.4 \\
\hline \multirow[t]{2}{*}{ Accipitriformes } & Buteo buteo & common buzzard & 4 & 1 & - \\
\hline & Aquila chrysaetos & golden eagle & 1 & 1 & - \\
\hline \multirow[t]{2}{*}{ Anseriformes } & Cygnus olor & mute swan & 12 & 2 & 16.6 \\
\hline & Anas platyrhynchos & wild duck & 3 & 0 & - \\
\hline \multirow[t]{2}{*}{ Charadriiformes } & Larus argentatus & European herring gull & 1 & 1 & - \\
\hline & Sterna hirundo & common tern & 1 & 1 & - \\
\hline Strigiformes & Strix aluco & tawny owl & 3 & 1 & - \\
\hline \multirow[t]{2}{*}{ Falconiformes } & Falco tinnunculus & common kestrel & 4 & 0 & - \\
\hline & Falco peregrinus & peregrine falcon & 2 & 0 & - \\
\hline Gruiformes & Grus grus & common crane & 1 & 0 & - \\
\hline Piciformes & Dendrocopos major & great spotted woodpecker & 10 & 1 & 10 \\
\hline Apodiformes & Apus apus & common swift & 2 & 0 & - \\
\hline \multirow[t]{17}{*}{ Passeriformes } & Corvus corax & common raven & 1 & 1 & - \\
\hline & Corvus monedula & western jackdaw & 14 & 4 & 28.6 \\
\hline & Pica pica & Eurasian magpie & 3 & 0 & - \\
\hline & Parus major & great tit & 4 & 4 & - \\
\hline & Fringilla coelebs & common chaffinch & 4 & 4 & - \\
\hline & Sylvia atricapilla & Eurasian blackcap & 2 & 1 & - \\
\hline & Erithacus rubecula & European robin & 27 & 0 & - \\
\hline & Phoenicurus ochruros & black redstart & 1 & 0 & - \\
\hline & Turdus philomelos & song thrush & 1 & 1 & - \\
\hline & Turdus merula & common blackbird & 2 & 0 & - \\
\hline & Regulus regulus & goldcrest & 4 & 0 & - \\
\hline & Periparus ater & coal tit & 2 & 0 & - \\
\hline & Fringilla montifringilla & brambling & 1 & 0 & - \\
\hline & Chloris chloris & European greenfinch & 1 & 0 & - \\
\hline & Cyanistes caeruleus & Eurasian blue tit & 4 & 0 & - \\
\hline & Poecile montanus & willow tit & 1 & 0 & - \\
\hline & Aegithalos caudatus & long-tailed tit & 1 & 0 & - \\
\hline Total: 12 & 32 & 32 & 192 & 58 & 30.2 \\
\hline
\end{tabular}

$*$ only if the number of birds tested $\geq 10$

Table 2. Samples of internal organs from wild birds tested by RT-PCR

\begin{tabular}{llll}
\hline Internal organ & $\begin{array}{l}\text { Number of } \\
\text { examined samples }\end{array}$ & $\begin{array}{l}\text { Number of } \\
\text { positive samples }\end{array}$ & $\begin{array}{l}\text { Percentage of } \\
\text { positive samples }\end{array}$ \\
\hline heart & 113 & 23 & 20.4 \\
lungs & 55 & 13 & 23.6 \\
liver & 130 & 8 & 6.2 \\
spleen & 63 & 13 & 20.6 \\
gizzard & 81 & 13 & 16.0 \\
intestines & 78 & 9 & 11.5 \\
kidneys & 52 & 9 & 17.3 \\
\hline Total & 572 & 88 & 15.4 \\
\hline
\end{tabular}


Table 3. The origin of homogenates used for infection of CEK culture cells, the results of ARV isolation and the RT-PCR test

\begin{tabular}{|c|c|c|c|}
\hline $\begin{array}{l}\text { Isolate of ARV } \\
\text { (identity no./year of } \\
\text { isolation/internal organ*/sample no.) }\end{array}$ & Host & $\mathrm{CPE}$ & RT-PCR \\
\hline $67 / 14 / \mathrm{j} / 5$ & common buzzard & + & + \\
\hline $67 / 14 / n / 9$ & white stork & - & + \\
\hline $67 / 14 / \mathrm{n} / 10$ & white stork & + & + \\
\hline $67 / 14 / \mathrm{j} / 6$ & rock pigeon & + & + \\
\hline $67 / 14 / \mathrm{n} / 3$ & grey heron & + & + \\
\hline $67 / 14 / n / 11$ & white stork & + & + \\
\hline $67 / 14 / w / 16$ & white stork & + & + \\
\hline $116 / 15 / z / 3$ & white stork & + & + \\
\hline $147 / 15 / \mathrm{n} / 5$ & white stork & + & + \\
\hline $147 / 15 / \mathrm{n} / 7$ & white stork & - & + \\
\hline $147 / 15 / \mathrm{p} / 3$ & white stork & + & + \\
\hline $147 / 15 / s / 4$ & white stork & + & + \\
\hline $147 / 15 / z / 4$ & white stork & + & + \\
\hline $22 / 16 / \mathrm{p} / 1$ & mute swan & - & - \\
\hline $22 / 16 / \mathrm{s} 1 / 1$ & great tit & - & - \\
\hline $22 / 16 / w / 1$ & common tern & - & - \\
\hline $119 / 16 / \mathrm{s} / 1$ & western jackdaw & - & - \\
\hline
\end{tabular}

* $\mathrm{j}$ - intestine, $\mathrm{n}$ - kidney, $\mathrm{w}$ - liver, $\mathrm{z}$ - gizzard, $\mathrm{p}$ - lung, $\mathrm{s}$ - heart, $\mathrm{sl}$ - spleen

The group-specific antigen of ARV was detected in hepatic homogenates, embryonic fluids, and membranes collected from 10 infected chicken embryos, which showed reactivity with specific S1133 chicken reovirus antibodies. It manifested through the precipitation lines between the examined antigen and standard serum (Fig. 1). To confirm the propagation of ARV in chicken SPF embryos, total RNAs were extracted from hepatic homogenates, embryonic fluids, and membranes collected from infected chicken SPF embryos, and RT-PCR was conducted in order to amplify $\sigma \mathrm{NS}$ gene fragment. Specific amplification products of predicted size were found in hepatic homogenate from chicken embryos infected with material from rock pigeon and in embryonic fluids and membranes collected from chicken embryos infected with material from white stork.

The selected homogenates of internal organs from 17 wild birds with positive result in RT-PCR were used for infection of CEK cells (Table 3). Three passages were conducted at $16-\mathrm{h}$ intervals. In the third passage, a $\mathrm{CPE}$ in the form of rounded cell focuses starting from the 72 to 120 h.p.i. was observed in 11 cell cultures. In a few cases, the cell culture loosening was observed. CPE indicating the presence of ARV was difficult to identify. The virus did not cause total disruption of the cell monolayer (Fig. 2). To confirm the propagation of ARVs from wild birds in CEK cell cultures, total RNA was extracted from cell culture supernatants, and amplification of $\sigma \mathrm{NS}$ gene sequences was conducted. A specific fragment of 522 bp was amplified from 13 isolated strains and the reference strain S1133. RNA extracted from non-infected cells was used as a negative control and no band was observed. In total, 13 ARV strains from 10 white storks, grey heron, common buzzards, and rock pigeon were obtained (Table 3). In the case of two cell cultures infected with material from white storks, no CEK was observed, with simultaneous confirmation of the presence of ARV genetic material in the RT-PCR assay.

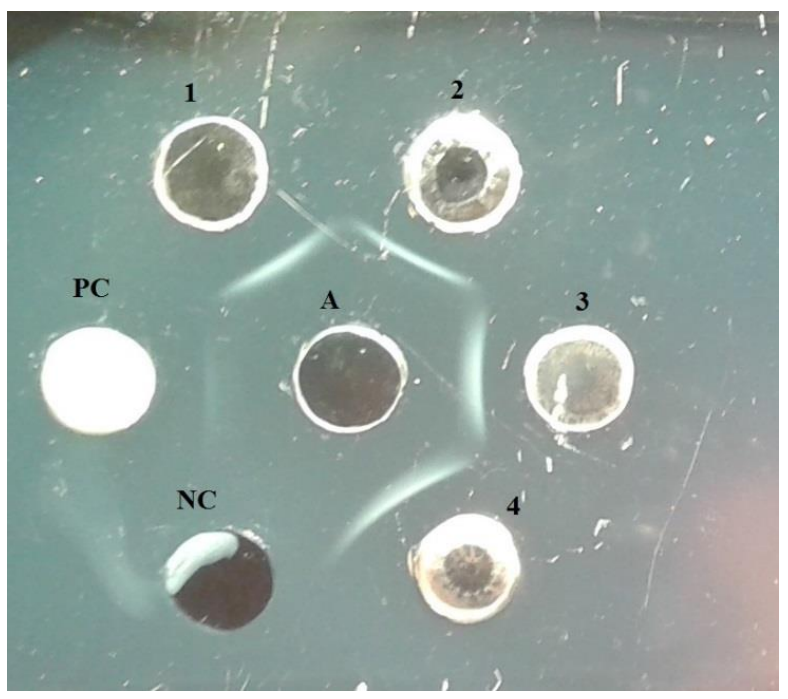

Fig. 1. Antigen-specific group of reovirus in agar gel immunodiffusion (AGID) test. PC - positive control S1133 chicken reovirus antigen (Charles River Laboratories, USA), NC - negative control, A - S1133 reovirus antiserum (Charles River Laboratories, USA), 1 - hepatic homogenate from chicken embryos infected with material from rock pigeon, 2 - embryonic fluids and membranes from chicken embryos infected with material from rock pigeon, 3 hepatic homogenate from chicken embryos infected with material from white stork, 4 - embryonic fluids and membranes from chicken embryos infected with material from white stork 

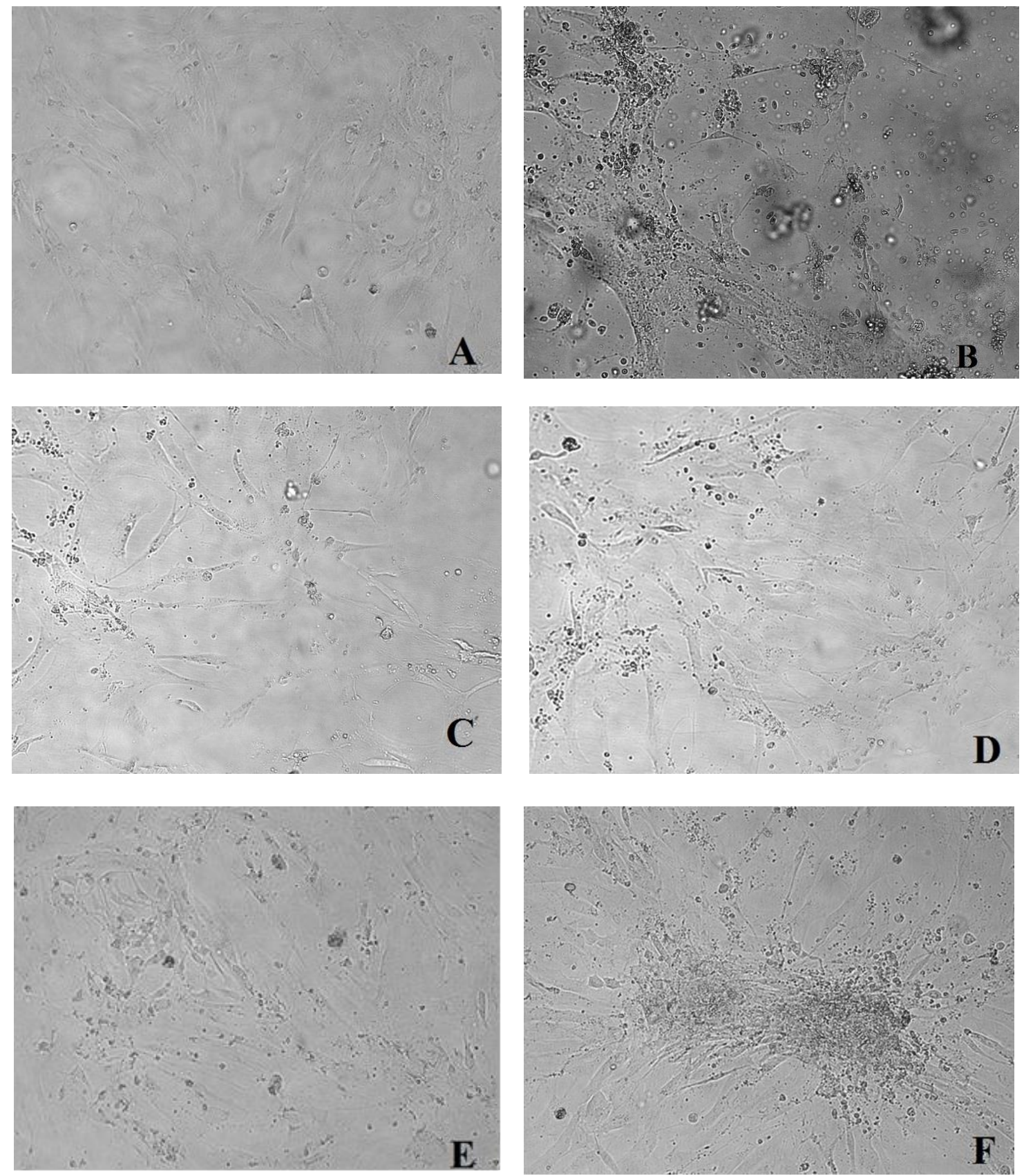

Fig. 2. Changes in chicken embryo kidney (CEK) cell cultures. Pictures taken at $72-120 \mathrm{~h}$ p.i. with the $3^{\text {rd }}$ virus passage.

A - negative control - non-infected CEK cells, B - CPE in CEK cells infected with reference strain S1133, C - CPE in CEK cells infected with homogenate of the kidney from grey heron, D - CPE in CEK cells infected with homogenate of the intestine from common kestrel, E - CPE in CEK cells infected with homogenate of the intestine from rock pigeon, F- CPE in CEK cells infected with homogenate of the kidney from white stork. 200× (Axio Observer D1, Zeiss, Germany)

\section{Discussion}

The epidemiology of ARV infections in wild birds remains unknown, so it was reasonable to conduct a study on their occurrence. The research was performed using molecular methods and classical virus isolation methods, which allowed us to obtain ARV strains for our departmental collection. ARV infections have been increasingly diagnosed in wild avian species. Recent reports have described ARV as a cause of serious disease and/or mortality in free-living corvid species in Great Britain and Finland $(5,10)$. ARV strain detected in a free-living magpie was genetically related to chicken origin reoviruses, reinforcing the hypothesis on the possible reservoir role of wild birds in reovirus transmission (10). Ogasawara et al. (18) isolated a novel orthoreovirus strain from a dead brown-eared bulbul (order Passeriformes) in Japan. Scientists from Hungary detected a reovirus strain isolated from partridge and conducted its genomic characterisation. Their results imply that partridges may serve as natural reservoirs of ARVs for domestic poultry (9). In 2011, ARV was detected in blackcapped chickadees (Poecile atricapillus) and molecular 
characterisation showed $89.4 \%-98.3 \%$ nucleotide identity to turkey reoviruses (16). In our study, ARVs were identified in over $30 \%$ of the wild birds investigated, highlighting a serious concern for farmed bird flocks. The largest group of birds belonged to Passeriformes and Ciconiiformes order, which made up $37.5 \%$ and $31.8 \%$ of the birds tested, respectively. The presence of ARV genetic material was detected in all types of the examined internal organs, which confirms the tropism of the virus to many organs and tissues. ARV infections were found in different species of wild birds, which might indicate their possible transmission to other birds inhabiting Poland.

One of the previous reports described reovirus infection of pheasants in the western part of Turkey, with clinical symptoms manifested as shortness of breath, greenish and watery diarrhoea, and death within a week (17). The material collected in our study did not allow us to observe clinical symptoms, because it was taken from dead birds.

ARV propagation using chicken embryos and CEK cell cultures are useful, although time-consuming, in virological diagnosis. The molecular biology methods targeting specific ARV genes have been shown effective in more rapid detection of ARV infections $(3,8,24)$. In the present study, ARVs were propagated in cell culture and chicken SPF embryos in order to confirm the results obtained by RT-PCR. ARVs from wild birds may be propagated on chicken embryos by yolk sac inoculation. They induce CPE in the infected CEK monolayer. ARV strains isolated from wild birds exhibit pathogenicity for chicken embryos, which was confirmed by the embryo pathological changes observed in the form of subcutaneous haemorrhages in the muscle tissue and changes in internal organs characteristic of reovirus infection. Changes in infected CEK cell cultures demonstrated effective replication of the virus. In several cell cultures infected with material from white storks, great tit, western jackdaw, and common tern, no CPE was observed after the third passage. It may be necessary to perform more passages or use a different type of cells for in vitro culture. In previous studies, a novel orthoreovirus isolated in BHK (baby hamster kidney-21 cells) from a diseased crow caused a strong CPE, including syncytium formation (5).

ARV can be readily differentiated from other viruses based on the presence of a group-specific antigen in AGID test. This serological method is the most common approach for ARV diagnosis. In our study, the common antigen to chicken reoviruses was detected in ARV isolates from rock pigeon and white stork using AGP method, which confirmed their propagation in chicken embryos. These results are similar to observations of reoviruses isolated from Muscovy ducks $(12,23)$.

It is possible that there are species-specific reovirus strains, although at least some of them are capable to induce cross-infections among species.
Experimental study has shown that reoviruses isolated from wedge-tailed eagle (Aquila audax) can be infective for chickens (7). This study requires further efforts to assess the potential pathogenicity of ARV strains isolated from wild birds for domestic poultry.

Conflict of Interests Statement: The authors declare that they there is no conflict of interests regarding the publication of this article.

Financial Disclosure Statement: The study was supported by Project KNOW No. K/02/0.1 "New molecular methods for diagnosis of poultry viral diseases".

Animal Rights Statement: None required.

Acknowledgements: The authors acknowledge the staff of the Bird Migration Research Station at the University of Gdańsk and Wild Birds Rehabilitation Centre in Bukwałd for sharing the wild birds used in this study.

\section{References}

1. Bányai K., Dandár E., Dorsey K.M., Mató T., Palya V.: The genomic constellation of a novel avian orthoreovirus strain associated with runting-stunting syndrome in broilers. Virus Genes 2011, 42, 82-89.

2. Benavente J., Martínez-Costas J.: Avian reovirus: structure and biology. Virus Res 2007, 123, 105-119.

3. Bruhn S., Bruckner L., Ottiger H.P.: Application of RT-PCR for the detection of avian reovirus contamination in avian viral vaccines. J Virol Methods 2005, 123, 179-186.

4. Hollmen T., Docherty D.E.: Orthoreovirus. In: Infectious Diseases of Wild Birds, edited by Thomas N.C., Hunter D.B., Atkinson C.T.: Blackwell Publishing, Iowa, USA, 2007, pp. 177-181.

5. Huhtamo E., Uzcátegui N.Y., Manni T., Munsterhjelm R., Brummer-Korvenkontio M., Vaheri A., Vapalahti O.: Novel orthoreovirus from diseased crow, Finland. Emerg Infect Dis 2007, 13, 1967-1969.

6. Jones R.C.: Reovirus infections. In: Diseases of Poultry, edited by Saif Y.M. et al., Blackwell, USA, 2008, pp. 309-328.

7. Jones R.C., Guneratne J.R.: The pathogenicity of some avian reoviruses with particular reference to tenosynovitis. Avian Pathol 1984, 13, 173-189.

8. Ke G.M., Cheng H.L., Ke L.Y., Ji W.T., Chulu J.L., Liao M.H., Chang T.J., Liu H.J.: Development of a quantitative light cycler real-time RT-PCR for detection of avian reovirus. J Virol Methods 2006, 133, 6-13.

9. Kugler R., Dandár E., Fehér E., Jakab F., Mató T., Palya V., Bányai K., Farkas S.L.: Phylogenetic analysis of a novel reassortant orthoreovirus strain detected in partridge (Perdix perdix). Virus Res 2016, 215, 99-103.

10. Lawson B., Dastjerdi A., Shah S., Everest D., Núñez A., Pocknell A., Hicks D., Horton D.L., Cunningham A.A., Irvine R.M.: Mortality associated with avian reovirus infection in a free-living magpie (Pica pica) in Great Britain. BMC Vet Res 2015, 11, 20, doi: 10.1186/s12917-015-0329-5.

11. Liu H.J., Lee L.H., Hsu H.W., Kuo L.C., Liao M.H.: Molecular evolution of avian reovirus: evidence for genetic diversity and reassortment of the S-class genome segments and multiple cocirculating lineages. Virology 2003, 314, 336-349. 
12. Liu Q., Zhang G., Huang Y., Ren G., Chen L., Gao J., Zhang D., Han B., Su W., Zhao J., Hu X., Su J.: Isolation and characterization of a reovirus causing spleen necrosis in Pekin ducklings. Vet Microbiol 2011, 148, 200-206.

13. Lu H., Tang Y., Dunn P.A., Wallner-Pendleton E.A., Lin L., Knoll E.A.: Isolation and molecular characterization of newly emerging avian reovirus variants and novel strains in Pennsylvania, USA, 2011-2014. Sci Rep 2015, 5, 1-11.

14. Martínez-Costas J., Grande A., Varela R., García-Martínez C., Benavente J.: Protein architecture of avian reovirus S1133 and identification of the cell attachment protein. J Virol 1997, 71, $59-64$.

15. Matthews R.: The classification and nomenclature of viruses: summary of results of meetings of the International Committee on Taxonomy of Viruses in Strasbourg, August 1981. Intervirology 1981, 16, 53-60.

16. Mor S.K., Armién A.G., Reed L., Schott R., Goyal S.M.: Detection and molecular characterization of a reovirus in blackcapped chickadees (Poecile atricapillus) from Minnesota, USA. J Wildl Dis 2014, 50, 928-932.

17. Mutlu O.F., Grund C., Cöven F.: Reovirus infection of pheasants (Phasianus colchicus). Tierarztl Prax Ausg G Grosstiere Nutztiere 1998, 2, 104-107.
18. Ogasawara Y., Ueda H., Kikuchi N., Kirisawa R.: Isolation and genomic characterization of a novel orthoreovirus from a browneared bulbul (Hypsipetes amaurotis) in Japan. J Gen Virol 2015, 96, 777-786.

19. Samorek-Salamonowicz E., Minta Z.: Zakażenia reowirusami (reovirus infections). In: Choroby drobiu, edited by Mazurkiewicz M., Wroclaw, 2011, pp. 464-470.

20. Spandidos D.A., Graham A.F.: Physical and chemical characterization of an avian reovirus. J Virol 1976, 19, 968-976.

21. Van der Heide L.: The history of avian reovirus. Avian Dis 2000, 44, 638-641.

22. Van Der Heide L.: Viral arthritis/tenosynovitis: a review. Avian Pathol 1977, 6, 271-284.

23. Woźniakowski G., Samorek-Salamonowicz E., Gaweł A.: Occurrence of reovirus infection in Muscovy ducks (Cairina moschata) in south western Poland. Pol J Vet Sci 2014, 17, 299-305.

24. Zhang Y., Liu M., Shuidong O., Hu Q.L., Guo D.C., Chen H.Y., Han Z.: Detection and identification of avian, duck, and goose reoviruses by RT-PCR: goose and duck reoviruses are part of the same genogroup in the genus Orthoreovirus. Arch Virol 2006, $151,1525-1538$ 